\title{
Connecting Individual Differences in Workforce to Organizational Creativity through Transformational Leadership for Corporate Transformational Effectiveness!
}

\author{
Syeda Asiya Zenab Kazmi, Marja Naaranoja* \\ Faculty of Technology, University of Vaasa, Vaasa, Finland \\ Email: asiyakazmi@hotmail.com, ${ }^{*}$ marja.naaranoja@uwasa.fi
}

Received August 13 $3^{\text {th }}, 2013$; revised September 15 ${ }^{\text {th }}, 2013$; accepted September $28^{\text {th }}, 2013$

\begin{abstract}
Copyright (C 2013 Syeda Asiya Zenab Kazmi, Marja Naaranoja. This is an open access article distributed under the Creative Commons Attribution License, which permits unrestricted use, distribution, and reproduction in any medium, provided the original work is properly cited.
\end{abstract}

The study offers grounds to measure level of "creativity" through directional "leadership management options" (i.e. transactional leadership, laissez-faire leadership) in teams marked by individual differences or diversity. The study results confirmed that transformational leadership provides support to generate creativity by even the ordinary performers marked by the workforce diversity phenomenon among the organizational workers.

Keywords: Creativity; Transactional Leadership; Laissez-Faire Leadership; Individual Differences; Transformational Leadership; Workforce Diversity

\section{Introduction}

Global awareness on the significance of good leadership is becoming increasingly apparent within the healthcare sector. It calls for an intense effort by the care leaders to function effectively by making conscious organizational working choices to ensure safety, and quality of care facilities. During recent times, management experts and researchers have focused significantly on searching innovative ways and means to provide strategic competitive choices for service sector industries to sustain. This demands change-driven process development. Consequently, what is needed is a mix of diverse leaders who can lead through these changes by promoting an environment suitable to encourage creativity.

Henceforth, the current research paper is an effort to measure the element of creativity linked with the workforce diversity within the case environment. In addition, the authors will investigate the relationship between creativity and the selected styles of "leadership" (i.e. transactional leadership, laissez-faire leadership and transformational leadership) in teams reflecting diversity as organizational competitive action.

The case study has the basis of a longitudinal research process, under way with the collaboration of the University of Vaasa and public sector policy formulators (i.e., Ministry of Health, Finland) through a Tekes supported project named OSUVA. The aim of the study is to suggest healthcare reforms in Finnish public sector through extensive human resource utilization targeting even the ordinary work performers by highlighting collaborative innovation. Scope of the current research investigation engulfed the current organizational situation through the dimensions of creativity, care (i.e., well-being), commitment, and confidence, to suggest leadership solutions to

${ }^{*}$ Corresponding author. manage the organizational transformation and improvement. On the whole, the case study is an effort to investigate the effective leadership style through which the "individual differences" among the team members can be effectively utilized to generate creativity initiatives as work forces' key potentials. The study findings justified the very fact that transformational leadership style provides strong grounds for gaining unique performance initiatives even by the ordinary performers within the organization's human resource cluster through diversity to promote creativity.

The article is arranged in a sequence that the authors will share the information on research settings initially, followed by throwing light on the literature review, hypothesis formulation, methodology used, and results of the study followed by the discussion and conclusion on the case study. We will end the paper by sharing the possible future avenues of the current research activity.

\section{Research Setting}

Our current study is a joint research venture between the public sector policy formulators (i.e., Ministry of Health, Finland, and the Faculty of Technology, University of Vaasa, Finland). The overall focus of the research initiative is to focus on to suggest healthcare reforms highlighting collaborative innovation and its continuous improvement thereafter for the maturity of the organizational transformation process. However, the current paper will focus on a limited view of the greater research parameters; which is, to investigate the effective leadership option to promote creativity through workforce diversity. In the current study, the localities, for which the transformational process is targeted, are the Vaasa, Laihia and Vähäkyrö areas situated in the north of Finland.

The proposed collaborative innovative change process was 
injected in to the work departments consisting on physiotherapy, dental units, child and mother care, general physician services at the targeted localities. Here, it is pertinent to mention that the services like, administration, physiotherapy, psychologist service and support services are jointly managed in the relatively distant targeted localities. In addition, the study sample represents diversity in terms of the respondents' professional as well as hierarchical standings within the case environment.

\section{Literature Review}

Transformational leadership has emerged from the need to transform the individual's abilities, team's performance level or the firm's potential to go beyond the expected gains. Transformational leadership is defined as the combination of four attributes; Charisma; a force to create and present positive futuristic vision; inspirational motivation; an inspirational spirit to motivate the followers to reach out beyond their self-interest; Intellectual stimulation; a spirit to prompt the followers to see the issues from a novel perspective to offer solutions; individualized consideration; an ability of the leader to develop the follower through encouragement, support and mentoring.

First introduced by Burns (1978) and later elaborated by Bass (1985) the basic logic behind the Transformational Leadership style. Transformational Leadership is characterized by a leader's ability to articulate a shared vision of the future, intellectually stimulate employees, and attend to individual differences in employees (Lowe, Kroeck, \& Sivasubramaniam, 1996). According to Bass (1985) the model of "Transformational Leadership", is regarded as one of the most suited framework by the theorist and researchers for the organization where the managements truly work to encourage their employees to perform beyond expectations. Burns (1978) introduced the concept of "Transformational leadership" and highlighted the difference between "Transactional Leadership" and "Transformational Leadership" initially.

According to Bass (1985) transformational leaders motivate followers to achieve performance beyond expectations through the transformational process of thought (i.e., Beliefs and values etc.) and behavior (i.e., Attitudes and attributes etc.). The traditional description of leadership is that it is a mere combination of human traits that a person is having by default (Stogdill, 1974). According to Kouzes \& Posner (1987), the road to great leadership that is common to successful leaders includes the ingredients that are Challenge the process: Inspire a shared vision, Enable others to act, Model the way and Encourage the heart.

In addition, Bass \& Avolio (1993) were of the opinion that, the global effort for survival of the fittest requires a potent style of leadership that exceeds the traditional styles of transactional leadership or laissez-faire leadership which is known as no leadership. Transactional leadership is known for mostly focusing on reinforcement. According to the study findings by Pearce and Sims Jr. (2002), collective leadership was considered as the most significant basis of the team effectiveness. The case study findings revealed the clear basis for an empirical claim that a highly cognized strategy for dispensing leadership components among the team members is likely to enrich team effectiveness manifolds. Concept of team as defined by Raelin (2003) suggests that a "Team" is the development of "leaderful" communities where leadership actually gets the basis to groom or flourish.

The core ingredient that enables a "Leader" to lead his or her team is undoubtedly the "Learning Process" to grasp the encountering situations and to help the followers to cope with such forces by functioning comfortably and effectively. Here the question arises that how the leaders should handle their groups or teams members' capabilities effectively while coping with the variety diversity in individual behaviors within the human resource clusters. Plato, 2000 years ago concluded that "No two persons are born exactly alike"; but each differs from the other in natural endowments, one being suited for one occupation and the other for another. Sir Francis Galton (1822-1911) proposed that why not measure human traits and then selectively breed superior people? He pointed towards human traits and covering the intellectual capability, physical ability, till the overall personality traits such as even-temperedness, as inherited. Individual differences are essential whenever we wish to explain how individuals differ in their behavior, performance level, capabilities and intellectual levels etc. (Buss \& Greiling, 1999). Finkelstein and Hambrick (1996) argue that the life experiences and psychological attributes of managers influence their view of the world resulting in differential behavior among executives facing similar circumstances'. Transformational leaders pay attention to individual and personal difference in needs development and growth and provide necessary resources to help followers to realize their dreams. Positive human resource management practices such as staffing, training, performance appraisal, and compensation systems are the means whereby leaders express their individual consideration of employees.

According to Bontis and Fitz-enz (2002), the human asset in an organization is a direct result of knowledge base, talent, and experiences attained by its diverse work force: Henceforth, the increased level of entrepreneurial drive further triggers the existence of distinguishable differences in individual entrepreneurial behavior (Armstrong \& Hird, 2009). While specifically emphasizing human capital, resource-based theory of the firm states that core competencies, in other words, rare, valuable, inimitable, and non-transferable human capital have greater potential to contribute to achieve and sustain competitive advantage through creativity (Prahalad \& Hamel, 1990). The findings of one case study by Pelz and Andrews (1976) on creativeness of engineers confirmed that the workers who maintained distinctive work styles and strategies are great sources of organizational creativity. Effective and continuous leadership retain the maximum potential to create suitable organizational climate that encourages and support creativity and innovation. Innovation correlates strongly with a person's perception of whether or not he is expected to be innovative.

\section{Hypothesis Formulations}

On the basis of literature review following hypotheses were tested:

- "Transformational leadership" is positively linked to creativity as compared with the other leadership or management directions (i.e., controlling or passive management or leadership).

- "Organizational creativity" is positively linked to work teams marked by individual differences.

\section{Methodology Used}

In the current case study, the authors combined the especially devised questionnaires having the open-ended queries, informal interviews and group discussions to investigate the current 
practices. Feedback from the selected sample size of 35 respondents representing the targeted localities (i.e., Laihia and Vähäkyrö) was obtained. The selected sample represented the cross hierarchical levels (i.e., senior management, line management and staff etc.) as well as multidisciplinary background (i.e., Physiotherapy units, Child and mother care units, Dentistry units or the general physician units etc.

In the research process, the authors selected transactional leadership and laissez-faire leadership styles against transformation leadership style, which is acknowledged as the leadership style to support organizational transformation through innovative processes (Avolio, Bass, \& Jung, 1999; Avolio, 1999; McShane \& VonGlinow, 2000).

The questions included in the research inventory were prepared to link the aspects of three styles of leadership (i.e; transactional leadership, transformational leadership and laissez-faire) with creativity and diversity to gauge their level of interconnectivity through their levels of presence in the current working environment. This exercise will further support the process of collaborative innovation, recently injected within the targeted work environments in the OSUVA project. The analysis of the research results included 35 respondents to investigate the current working practices and their impact on the aimed process of organizational transformation initiatives in the OSUVA project.

The properties used in the current research process are as follows:

- Accurate measurement of exposure level of three different leadership styles (i.e., transactional leadership, laissez-faire leadership and transformation leadership),

- Measurement of expected connection between the impact of transformational leadership and individual differences,

- The level of group member's desire to change overall performance through their participatory creative actions.

\section{Research Results}

To analyze the effects of tri-dimensional leadership on the target sample, having the mix of Individual Differences (ID), linking creativity aspect, specialized question statements were designed to test the hypotheses:

Table 1 reflects of sample questions areas on leadership trends with the linkage of creativity and individual difference aspects with specific reference to the target environment. In addition, the question items shown in Table 1 included in the research inventory, took the leadership theme from Multifactor Leadership Questionnaire, short form introduced by Bass and Avolio (1992) through modification according to the study needs i.e., to trigger variety in performance patterns by the respondents reflecting the basis of individual difference.

The research results on the basis of respondents' response patterns for the desired leadership process with regards to the attractiveness among three management leadership styles (i.e., transactional leadership, laissez-faire leadership styles and transformation leadership style) to support organizational creativity through individual differences are as follows.

The study results constituting the above figure, confirms the desired attractiveness for "Transformational Leadership" against transactional leadership or laissez-faire leadership styles to support organizational creativity through unique individual efforts. $76 \%$ of the respondents reflected their dissatisfaction over the current management style referring it as too controlled
Table 1.

Sample question based on three types of leadership styles (i.e., transactional leadership and laissez-faire leadership styles against transformation leadership) to identify the best fit of leadership trend to trigger creativity aspect highlighting individual difference among the workforce.

\begin{tabular}{|c|c|}
\hline Sr. No. & $\begin{array}{l}\text { Sample Question Items reflecting three management } \\
\text { leadership styles: }\end{array}$ \\
\hline 1 & $\begin{array}{l}\text { Describe your involvement in your organization's curren } \\
\text { innovation process? }\end{array}$ \\
\hline 2 & Describe your organization's leadership culture? \\
\hline 3 & $\begin{array}{l}\text { How would you rate the current level of trust between you } \\
\text { and your supervisor? }\end{array}$ \\
\hline 4 & $\begin{array}{l}\text { How usually you share any new idea about work improve- } \\
\text { ment proposal if it comes to your mind? }\end{array}$ \\
\hline 5 & $\begin{array}{l}\text { What factors do you think contribute in the level of trus } \\
\text { between the employee and the supervisor? Stress to achieve } \\
\text { the targets? }\end{array}$ \\
\hline 6 & How would you rate your job autonomy? \\
\hline 7 & $\begin{array}{l}\text { Did the senior management take your opinion on focused } \\
\text { areas while framing the rules for the new co-operation area? }\end{array}$ \\
\hline 8 & $\begin{array}{l}\text { What you feel has changed, in the new cooperation area } \\
\text { which could not be considered as having positive impact? }\end{array}$ \\
\hline 9 & $\begin{array}{l}\text { How to co-operate to promote employees' sense of com- } \\
\text { mitment at work? }\end{array}$ \\
\hline 10 & How passionately you feel about your work? \\
\hline 11 & $\begin{array}{l}\text { Are you doing exactly what motivates you to do at the work } \\
\text { place? }\end{array}$ \\
\hline 12 & $\begin{array}{l}\text { How management supports and encourages employee par- } \\
\text { ticipation in innovation? }\end{array}$ \\
\hline 13 & $\begin{array}{l}\text { How would you describe the confidence level as part of the } \\
\text { relationship between employee and supervisor? }\end{array}$ \\
\hline 14 & Why you are working at this health center? \\
\hline 15 & $\begin{array}{l}\text { Could you tell some examples of innovation that you've been } \\
\text { involved in producing a profit area here? }\end{array}$ \\
\hline 16 & $\begin{array}{l}\text { What is your understanding about innovation and how to } \\
\text { evaluate its significance as part of your work? }\end{array}$ \\
\hline
\end{tabular}

to encourage and promote creativity, due to the pressures like rush of work and lengthy reporting hierarchical processes and channels. The $62 \%$ respondents comments reflected their desire for transformational leadership style of management, $24 \%$ supported transactional style of leadership while $14 \%$ respondents favored laissez-faire leadership by refusing to offer comments. Few responses by the case respondents to justify the above finding are quoted below where the respondents remarked at the current controlling management style as a source of blockage or slowdown in creative thinking process within the case environment.

Response Examples:

- When new idea arises- we think for a very long time and if we find it really worthy enough only then share with supervisors or colleagues.

- I contribute to the innovation process, currently very little; only where it is possible though currently the resources are very limited.

- I feel that innovation here can be managed only if more workforces be provided.

- Monthly meetings are the source of exchanging work related ideas here; however, it takes weeks and months to arrange a meeting for some out of routine exchanges of views.

The results reflected through Figure 1 and the above box with the respondents' remarks, confirmed that the lack of creative initiatives in the case environment are mostly due to the 


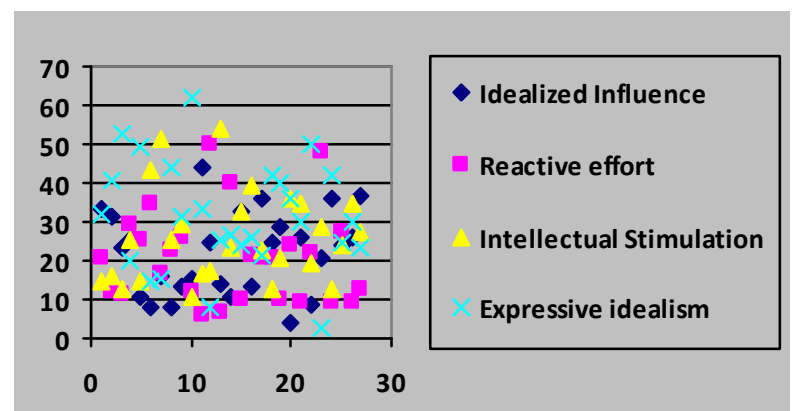

Figure 1.

Results reflecting for the desired Leadership process with regards to the three Management leadership styles to promote creativity through diversity in workforce.

transactional and laissez-faire leadership styles being implemented there. Furthermore, the above confirms that the absence of transformational leadership from the case environment causes the lack of creative initiatives by the reporting staff. This confirms the first hypothesis of the case study confirming the positive linkage between creativity and transformational leadership style.

On the basis of the variety among the respondents' response behaviors and character reflections, the authors have divided them into four categories; Action initiators, Conscious thinkers, Risk aversive, and Smart reactors (but late starters). The figure below reflects the results patterns of the respondents of through their responses after being exposed to the management leadership styles related feedback sessions through open discussions and interviews. The respondents are denoted by the first two alphabets of their corresponding behavioral categories in Figures 1 and 2 (i.e., AI for Action Initiators, CT for Conscious thinkers, RA for Risk Aversive and SR or Smart reactors).

The figure below represents the respondents' behavior wise categorization, in terms of transformational leadership's four dimensional scale (i.e., Idealized Influence, Inspirational Motivation, intellectual stimulation, and Individualized Consideration):

Since our earlier hypothesis confirmation, revealed the case environment as being highly dominated by transactional style of leadership, the next phase of study results, displayed through Figure 2 further confirmed low level of action initiation initiative i.e., $21 \%$, and high levels of risk averseness i.e., $38 \%$ followed by conscious thinking i.e., $23 \%$ amongst the respondents' behavior patterns. In addition, $19 \%$ behavior pattern presence was noted on smart reactors category of the respondents.

\section{Response Example:}

- Thinking about new ideas is easy but implementation is difficult, time is a limitation to collaborate for innovation.

- First think and then take it to the supervisors- - Physiotherapy is an independent task so the personal authority is available" reflected lack of trust on seniors.

The study results highlighted through represented the underlying concept of "differential psychology" by providing clear evidences for the role of "individual differences", (i.e., here in the form of smart reactors), among the human behavior patterns through their responses, as the result of the differences in their personality, traits, upbringing, earlier experiences intellectual levels etc.

The previous response example negates the targeted work

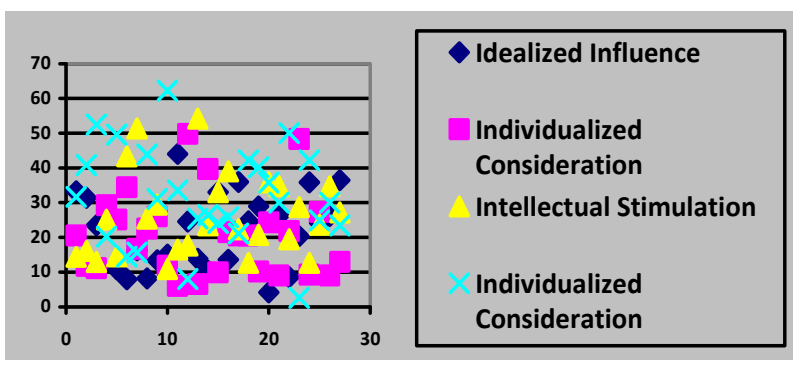

Figure 2.

Results reflect the impact of leadership on the performance levels of study participants, through four leadership dimensions highlighted by Bass (1985).

environments as supportive towards innovation and creativity. A significant factor which is linked positively to innovation is the degree to which the organizational workforce retains enjoys the freedom to exert influence upon decision making (Pelz \& Andrews, 1976).

In the study, the prominent examples are the behavioral patterns shown by the respondents' category "smart reactors (SR)". The respondents belonging to the SR category showed low responsiveness towards "intellectual stimulation" and "inspirational motivation" though they do not lack confidence level. However, the responded like action initiator category, responding sharply to "intellectual stimulation" and "inspirational motivation". The comparative response patterns shown by the respondent numbers 1, 5, 11, 18, 21 and 30 are the case examples of the smart reactors, proving the presence of individual differences or the impact of diversity.

\section{Response Example:}

- I use balance score card method as a judgmental tool for decision making with in my working area as an individual initiatives

- I use my personally designed methods of bandages application on the patients.

In addition, respondent's numbers 2, 7, 15, 20, 23, 33 and 34 categorized as "action initiators" reflected lower levels on "Individual efforts" which is contradictory pattern of behavior for their associated category affiliation. It again proves the presence of individual differences where the respondents acted differently from their usual response patterns. The highlight of the response pattern shown by the respondents category of "smart reactors" is that they initially behaved like late starters as in the cases of "risk aversive" or the "conscious thinkers", by reacting lower on "intellectual stimulation" and "inspirational motivation". However, with the passage of time, the smart reactors radically changed their response patterns by matching the ones similar to the "action initiators" i.e., reacting more to "intellectual stimulation" and "inspirational motivation".

Conscious thinker category (i.e., respondent number, 3, 4, 6, $9,10,13,19$ and 32) showed low responsiveness towards inspirational motivation and further showed reduced levels of responsiveness towards intellectual stimulation. Such behavior pattern showed reliance on the elements like, "management by exception" as well as "contingent reward" as key resources for planning.

In general, the respondents belonging to the "risk averse" category showed low responsiveness towards "intellectual stimulation". According to the study results respondents numbers 8 , $12,14,16,17,22,24,25,26$ and 27 fell in the risk aversive 
category by responding favorably to the category of management by exception, which is a contrasting behavior than that was expected from them, confirming the logic of "individual differences" or diversity factor once again.

Case examples for the above referred responds styles are that when one respondent mentioned her effort to initiate the usage of balance score card method or similar specialized skills within their work departments on their own initiatives. This confirms the individual differences as a source of organizational creativity through supportive leadership style i.e., transformational leadership. Henceforth, the above, in addition to the results reflection through Figure 2 proved the second hypothesis of the case study:

\section{Creativity is positively linked with the individual differ-} ences through transformational leadership.

The general trend reflected through the results of the study confirmed the enhanced levels of desire for "transformational leadership" in comparison with the passive and controlling management styles as a solution for creativity, by almost all the study participants.

\section{Discussion and Conclusion}

The study provides basis for the implementation of "transformational leadership" as being the attractive management choice amongst the other management choices (i.e., Passive Management and the Controlling Management styles) to achieve the maximum level of group members attention and effort to display personal actions of organizational creativity through their working behaviors. Though, the study revealed evidences of "individual differences" in few cases by certain employees (e.g., using balance score card methods or similar creative initiatives on their own) seems as an uncontrolled phenomenon to support creativity since the present organizational management style is predominantly characterized either as controlling or passive management styles.

Henceforth, the above facts convinced the authors that if such evidences can occur in the organizational environment, which is heavily dominated by controlling style of management, then so much more creative work patterns can be promoted through transformational leadership in the organizational working environment.

In addition, the research method which was introduced in the study provided a general framework for the management experts as a solution for maximum utilization of their human resources through effective selection of management style and protecting the workforce diversity to promote and display organizational creativity and effective human resource utilization to ensure industrial operational effectiveness. The authors conclude the study done by quoting Pelz and Andrews (1976):

A research team with members having diverse backgrounds helps building effectively stimulating intellectual work environment that can offer the analysis of problems from a broader perspective and guide to offer innovative ways of problems solving.

\section{Future Research Avenues}

Our research effort can open following avenues for further research and testing:

- How to establish the in-house management capacity to develop optimal work teams during the emergency tasks?

- Can a single method for resource development be considered useful for all types of Industrial set-ups (i.e., services and production industries)?

The same research results can be re-validated by the use of aggressive statistical methods to extend the study.

\section{REFERENCES}

Armstrong, S., \& Hird, A. (2009). Cognitive style and entrepreneurial drive of new and mature business owner-managers. Journal of Business Psychology, 24, 419-430. http://dx.doi.org/10.1007/s10869-009-9114-4

Avolio, B. J., Bass, B. M., \& Jung, D. I. (1999). Re-examining the components of transformational and transactional leadership using the Multifactor Leadership Questionnaire. Journal of Occupational and Organisational Psychology, 72, 441-462.

Avolio, B. J. (1999). Full leadership development: Building the vital forces in organizations. Thousand Oaks, CA: Sage.

Bass, B. M., \& Avolio B. J. (1993). Transformational leadership: A response to critiques. In M. M. Chemers, \& A. R. Ayman (Eds.), Leadership theory \& research perspectives and directions (pp. 4980). Sandiego, CA: Academic Press.

Bass, B. M. (1985). Leadership and performance beyond expectations. New York: Free Press.

Bontis, N., Fitz-enz, J. (2002). Intellectual capital ROI: A causal map of human capital antecedents and consequences. Journal of Intellectual Capital, 3, 223-247. http://dx.doi.org/10.1108/14691930210435589

Burns, J. M. (1978). Leadership. New York: Harper \& Row.

Buss, D. M., \& Greiling, H. (1999). Adaptive individual differences. Journal of Personality, 67, 209-243. http://dx.doi.org/10.1111/1467-6494.00053

Finkelstein, S., \& Hambrick, D. C. (1996). Strategic leadership: Top executives and their effects on organizations. St. Paul, MN: West Educational.

Kouzes, J. M., \& Posner, B. Z. (1987). Ref. Military Leadership (1993). FM 22-100. San Francisco, CA: W. H. Freeman, Jossey-Bass.

Lowe, K. B., Kroeck, K. G., \& Sivasubramaniam, N. (1996). Effectiveness correlates of transformational leadership and transactional leadership: A meta-analytic review. The Leadership Quarterly, 7, 385-425. http://dx.doi.org/10.1016/S1048-9843(96)90027-2

McShane, S. L., \& Von Glinow, M. A. (2000). Organizational behavior: Emerging realities for the workplace revolution. Boston, MA: McGraw-Hill.

Pearce, C. L., \& Sims Jr., H. P. (2002). Vertical versus shared leadership as predictors of the effectiveness of change management teams: An examination of aversive, directive, transactional, transformational, and empowering leader behaviors. Group Dynamics: Theory, Research, and Practice, 6, 172-197.

Pelz, D. C., \& Andrews, F. M. (1976). Scientists in organizations: Productive climates for research and development. Ann Arbor, MI: University of Michigan.

Prahalad, C. K., \& Hamel, G. (1990). The core competence of the corporation. Harvard Business Review, 68, 78-91.

Raelin, J. A. (2003). Creating leaderful organizations: How to bring out leadership in everyone (p. 290). San Francisco, CA: BerrettKoehler.

Stogdill, R. M. (1974). Handbook of leadership: A survey of the literature. New York: Free Press. 